\title{
Avaliação digital comparativa da expressão tecidual da proteina cerbB-2 em mulheres portadoras de doenças tumorais da mama
}

\author{
Comparative digital evaluation of tissue expression of the cerbB-2 protein in women with breast \\ tumoral diseases
}

Renata Kelly de Araújo Veiga ${ }^{1 ;}$ Mario Ribeiro de Melo-Júnior ${ }^{1,2}$; Jorge Luiz Silva Araújo Filho'; Consuelo Antunes Barreto Lins ${ }^{3}$; Nicodemos Teles ${ }^{1,4}$

\begin{abstract}
unitermos
Câncer de mama

CerbB-2

Her-2/neu

Análise de imagens

\section{resumo}

A imuno-histoquímica (IHC) para expressão da proteína Her-2/neu tornou-se um dos mais atrativos testes de rotina, devido a custo, conveniência e relevância biológica. Contudo, têm sido relatados problemas quanto à variabilidade das marcaç̃̃es em IHC, além da subjetividade na interpretação dos métodos de IHC convencionais. Assim, o presente estudo objetiva quantificar morfometricamente a imunomarcação da proteína cerbB-2 expressa em tumores de mama. Fragmentos de tecido mamário normal $(n=10)$ e com doença tumoral (carcinoma ductal invasivo [CDI], $n=51$ e fibroadenoma, [FA], $n=21$ ) foram fixados em formalina, submetidos à rotina histológica para inclusão em parafina. Cortes histológicos $(4 \mu \mathrm{m})$, corados em hematoxilina e eosina foram examinados para confirmar o diagnóstico. Os cortes foram incubados em solução de anticorpo anti-cerbB-2 por 60 minutos em temperatura ambiente. A marcação foi visualizada após reação da peroxidase do cromógeno diaminobenzidina associado ao peróxido de hidrogênio. A análise morfométrica foi realizada utilizando uma estação de análise digital de imagens por meio do software de análise Optimas ${ }^{\circledR}$. A partir dos resultados obtidos, pode-se concluir que a superexpressão do cerbB-2 em casos de CDI é um fenômeno condizente com o estágio de proliferação das células neoplásicas e, quando analisados os casos de FA, esse marcador não exibiu qualquer correlação ou padrão específico; ao contrário, apresentaram resultados semelhantes ao tecido mamário normal. Não houve diferenças significativas entre os diferentes score qualitativos (1+, 2+ e 3+) e a análise morfométrica digital (áreas médias marcadas). Esses achados demonstram a necessidade de estudos mais acurados a fim de resolver essa dificuldade de interpretação.
\end{abstract}

\section{abstract}

Immunohistochemistry for HER-2/neu protein expression has become the most attractive routine test due to its cost, convenience and biological relevance. However, problems as to IHC staining variability and subjectivity in the interpretation of IHC conventional methods have been reported. Thus, this study aims to quantify morphometrically cerbB-2 protein immunostaining expressed in breast tumors. Mammary fragments of normal breast tissue $(\mathrm{n}=10)$ and with tumoral disease (invasive ductal carcinoma, IDC, $\mathrm{n}=51$ and fibroadenoma, $F A, n=21)$ were fixed in formalin, processed histologically and embedded in paraffin. Hematoxylin and eosin stained sections (4 mm) were examined to confirm the diagnosis. Afterwards, they were incubated with anti-cerbB-2 antibody solution for 60 minutes at room temperature. The staining was visualized after the peroxidase reaction with diaminobenzidine chromogen associated with hydrogen peroxide. Morphometric analysis was carried out using a digital image analysis workstation based on OPTIMAS ${ }^{\circledR}$ software. From these results it may be concluded that cerbB-2 over expression in IDC cases is a phenomenon closely related to the stage of neoplastic cell proliferation. When FA cases were analyzed, this marker did not show any correlation with the staining pattern. On the contrary, FA and normal mammary tissue analysis yielded similar results. There were no significant differences between the different qualitative scores (1+, 2+ and 3+) and digital morphometric analysis (marked mean areas). These findings suggest the necessity for more accurate studies in order to clarify this interpretation issue.

\section{key words}

Breast cancer

CerbB-2

Her-2-neu

Image analysis

1. Pesquisador(a) do Setor de Patologia do Laboratório de Imunopatologia Keizo Asami da Universidade Federal de Pernambuco (LIKA/UFPE);

2. Professor adjunto da Associação Caruaruense de Ensino Superior (ASCES).

3. Patologista da Universidade de Pernambuco (UPE)

4. Professor titular do Departamento de Patologia da UFPE. 


\section{Introdução}

Ante a dificuldade de eliminar o câncer instalado, cada vez mais os oncologistas utilizam a avaliação de marcadores tumorais para nortear sua conduta quanto ao tratamento dos pacientes e, posteriormente, para acompanhar a eficácia do mesmo ${ }^{(7)}$.

Os marcadores tumorais são substâncias presentes no tumor, no sangue ou em outros líquidos biológicos, produzidos primariamente pelo tumor ou secundariamente pelo paciente, em resposta à presença do tumor ${ }^{(19)}$. A caracterização e quantificação dessas substâncias têm se mostrado de grande importância para a evolução da oncologia, visto que, por meio dos resultados de inúmeros estudos, pode-se hoje tratar os pacientes de maneira mais direcionada e, consequentemente, esse tratamento tende a ter uma maior eficácia ${ }^{(8)}$.

A proteína cerbB-2 é um dos marcadores atualmente utilizados na patologia para a avaliação de tumores malignos da mama. É um receptor glicoproteico transmembrana, com peso de $185 \mathrm{KDa}$ e codificado pelo protooncogene erbB-2, localizado no cromossomo 17 q21 (15). Esse receptor, homólogo ao do fator de crescimento epidermal, quando ligado funciona transmitindo sinais para a proliferação, migração, adesão e transformação celular $^{(16)}$. Por isso, a ativação anômala do gene erbB-2 leva à exacerbação das funções sinalizadas pela proteína cerbB-2.

Cerca de $20 \%$ a $30 \%$ dos carcinomas ductais (CD) e $40 \%$ a $70 \%$ das lesões intraductais apresentam superexpressão de cerbB-2 ${ }^{(22)}$, e essa expressão está correlacionada a um fenótipo mais agressivo(9). Tem sido demonstrado por alguns autores que pacientes portadoras de câncer de mama e com alta expressão de cerbB-2 têm baixa resposta à terapia hormonal $(\mathrm{TH})$, principalmente aquelas pacientes em que já ocorreu metástase ${ }^{(30)}$.

O cerbB-2 é atualmente um marcador tumoral bastante pesquisado por meio da imuno-histoquímica; no entanto, embora o seu correto diagnóstico seja crucial para o direcionamento terapêutico, não existem parâmetros diagnósticos precisos para quantificar os padrões de marcação dessa proteína nos tecidos, sendo então utilizada uma análise subjetiva e qualitativa(21).

Além disso, não foram encontrados na literatura disponível relatos de avaliações que utilizam sistemas morfométricos em busca de uma quantificação desses parâmetros imunohistoquímicos.
Diante de tal fato, este estudo se propõe a avaliar, de forma comparativa, o padrão de marcação imunohistoquímica em amostras de mama de mulheres com carcinoma ductal invasivo (CDI) e fibroadenoma (FA) pelos métodos de avaliação semiquantitativa por microscopia de luz convencional e análise digital de imagem. Além disso, pretende-se investigar os padrões de expressão tecidual da proteína cerbB-2 entre as diferentes lesões tumorais estudadas.

\section{Metodologia}

\section{Amostras de tecido}

Foram selecionados 62 blocos de parafina com fragmentos teciduais (biópsias ou ressecção cirúrgica $[\mathrm{RC}]$ ) de pacientes do sexo feminino, com idades entre 17 e 70 anos, atendidas entre os anos de 2005 e 2006, em um laboratório privado de Recife e Laboratório de Imunopatologia Keiso Asami (LIKA), órgão suplementar da Universidade Federal de Pernambuco (UFPE), com diagnóstico CDI, $n=51 \mathrm{e}$ FA, $n=21$. Os casos de mama normal $(n=10)$ analisados no trabalho foram obtidos a partir das margens teciduais livres dos tumores.

\section{Estudo histológico e imuno-histoquímico}

A partir dos blocos selecionados, foram retirados cortes histológicos medindo $4 \mu \mathrm{m}$, montados em lâminas silanizadas e corados com hematoxilina-eosina (HE), e então revisados por um patologista (C.A.B.L.).

Para a reação imuno-histoquímica, os cortes foram previamente montados em lâminas silanizadas e desparafinizados pela ação do xilol em dois banhos de cinco minutos à temperatura ambiente (TA), hidratados com etanol 100\% e lavados em água corrente e destilada. Em seguida, precedeu-se a recuperação antigênica, incubando-se as lâminas em solução tampão citrato de sódio $10 \mathrm{mM} / \mathrm{pH}$ 6, em vapor úmido por 30 min a $100^{\circ}$, depois lavadas (por cinco min) com solução salina tamponada com fosfato (PBS) e leite Molico $^{\circledR}$ (a fim de evitar reações cruzadas).

Logo após, foi realizado o bloqueio da peroxidase endógena com peróxido de hidrogênio $\left(\mathrm{H}_{2} \mathrm{O}_{2}\right)$ a $3 \% \mathrm{em}$ metanol (dois banhos de $10 \mathrm{~min}$ ), seguindo-se as lavagens em água corrente e destilada e PBS $0,015 \mathrm{~mol} / \mathrm{L} \mathrm{com} \mathrm{pH}$ 7,8 . Posteriormente os cortes foram incubados com anticorpo monoclonal anti-cerbB-2 (CB11 DAKO/USA) diluído a 1:800 por 30 min em TA; lavados em tampão PBS $(3 \times$ $3 \mathrm{~min}$ ); incubados com o anticorpo secundário biotinilado 
(Kit LSAB DAKO/USA) por 15 min à TA e novamente lavados com tampão PBS. Para revelação da reação, incubaram-se as lâminas em solução de diaminobenzidina (DAB) 60 mg\% por 10 min à TA e ao abrigo da luz. Nessa etapa, a DAB reage com a peroxidase produzindo uma coloração marrom característica da positividade do ensaio imunohistoquímico. Para finalização do processo, as lâminas foram lavadas em água destilada e corrente, contracoradas com hematoxilina, montadas com Entelan ${ }^{\circledR}$ e, após secas, foram levadas ao microscópio de luz para análise.

\section{Análise digital de imagens}

As imagens digitalizadas foram obtidas utilizando-se um programa de captura e análise automática de imagens (Bioscan $^{\circledast}$, Image hyperlink ${ }^{\circledast}$ e Optimetric ${ }^{\circledR}$ ) interligado a uma câmara de vídeo JVC, modelo CV - 730, e essa a um microscópio (Leica, modelo ATC 2000). As funções matemáticas para medidas morfológicas, tais como número de partículas e área média, foram executadas automaticamente pelo programa Optimas ${ }^{\circledR} 6.1$ (Optimas Corporation, USA).

Os perfis de marcação da imuno-histoquímica (magnificação 200x) revelados pela reação do $D A B$ + peroxidase foram captados pelo ajuste do contraste do nível de cinza (gray value). A partir da captura das imagens dos tecidos marcados com o cerbB-2 e posterior conversão para escala de cinza, foram selecionadas as áreas a serem contadas por meio do ajuste de calibração manual (threshold range).

O parâmetro morfométrico adotado foi área média total $\left(\mu \mathrm{m}^{2}\right)$ composta pelo número de partículas (perfil de marcação da imuno-histoquímica em número de pixels das imagens) por campo captado (área total de $12.234 \mu^{2}$ ) na preparação histológica. A análise quantitativa das células marcadas por campo histológico foi realizada utilizando sistema automático e estudando-se três campos em cada caso.

Para fins comparativos, os mesmos campos histológicos foram avaliados qualitativamente, de acordo com a classificação do fabricante do kit utilizado(6). Essa análise foi realizada por um patologista cego ao estudo.

Para minimizar distorções nos valores das medições devido à presença de células não-marcadas, aplicou-se um fator de correção (FC) de acordo com a equação $F C=s / S$, onde $s$ é o valor da área superficial marcada e $S$, a área total medida ${ }^{(29)}$.
Os dados obtidos foram analisados estatisticamente, utilizando o teste de Tukey, para um nível de significância $(p<0,05)$. A eficiência desse teste foi avaliada por meio do índice J (índice de Youden), pelo qual foi constatado que $100 \%$ dos dados obtidos podem ser testados pelo método pós-analítico para comparações múltiplas.

\section{Resultados}

A idade média das pacientes com diagnóstico de CDI foi de 52 anos, enquanto os casos de FA apresentaram uma idade média de 36 anos (Tabela 1). Assim, nos casos analisados neste estudo, houve uma prevalência da lesão benigna ( $F A$ ) em mulheres mais jovens, na faixa etária entre 30 e 45 anos.

Neste trabalho, observou-se que $76 \%$ dos casos de CDI apresentaram marcação positiva para cerbB-2 com padrão exclusivamente membranar (Figura 1). No entanto, não foi observada a expressão do cerbB-2 nos casos de FA nem nas amostras de mama normal.

$\mathrm{Na}$ análise quantitativa dos padrões de marcação da proteína cerbB-2, os resultados obtidos pela análise de imagem das amostras demonstraram não haver diferença estatisticamente significativa entre o número de áreas marcadas do tecido normal $(19 \pm 4,2)$ e do CDI negativo para a expressão de cerbB-2 (46 \pm 23$)$; no entanto, houve diferença entre esses dois grupos e o CDI com expressão tecidual positiva para a proteína (408 \pm 157$)$.

$\mathrm{Na}$ análise qualitativa, quando foi investigada a relação entre os três possíveis diagnósticos positivos do método de avaliação semiquantitativa por microscopia de luz para cerbB-2 $(1+, 2+$ e $3+)$, constatou-se que os resultados quantitativos do número médio de áreas marcadas, obtidos pela análise de imagens, não apresentaram diferenças estatisticamente significativas (Figura 2).

Distribuição etária das lesões tumorais Tabela 1 da mama

Faixa etária/anos (\%)

$\begin{array}{lcccc}\text { Lesão } & 15-29 & 30-45 & 46-60 & >60 \\ \text { CDI(-) } & - & 3(25) & 5(42) & 4(33) \\ \text { CDI(+) } & 1(3) & 11(28) & 14(36) & 13(33) \\ \text { FA } & 9(36) & 7(45) & 5(18) & -\end{array}$

CDI: carcinoma ductal invasivo; FA: fibroadenoma. 


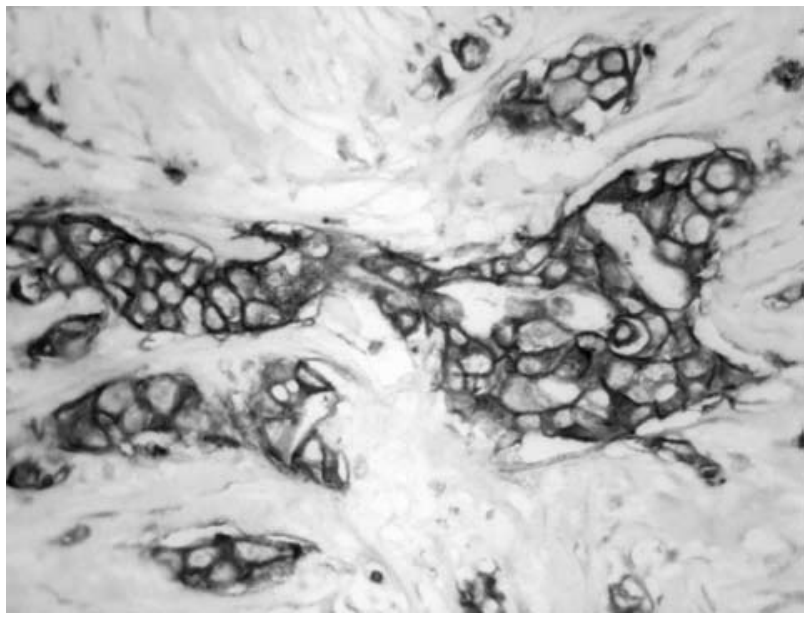

Figura 1 - Padrão membranar da imunoexpressão da proteína cerb-2 em carcinoma ductal infiltrante (CDI). Magnificação 200x

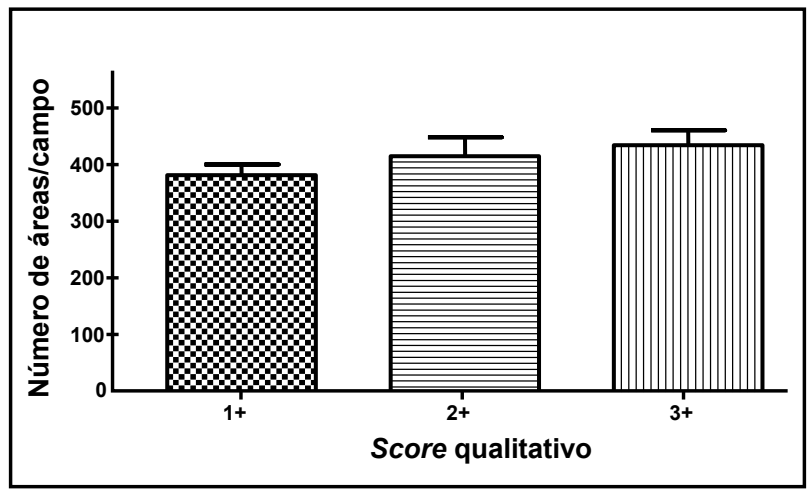

Figura 2 - Análise comparativa entre score qualitativo e análise de imagens da expressão tecidual da proteína cerbB-2

\section{Discussão}

A expressão anômala ou exagerada de algumas dessas substâncias biológicas pode estar presente em neoplasias malignas da mama, apresentando relevância do ponto de vista prognóstico. Os fatores biológicos mais implicados com o prognóstico em câncer de mama são os receptores hormonais de estrógeno e progesterona, a expressão anômala da proteína p53 e a superexpressão do receptor do fator de crescimento epidérmico humano (HER-2/neu ou cerbB-2) (24).

A expressão aumentada da proteína cerbB-2, detectada por imuno-histoquímica, ocorre em cerca de $20 \%$ de todos os cânceres de mama. Analisando separadamente os tipos histológicos, estudos demonstram a superexpressão da cerbB- 2 em $20 \%$ a $30 \%$ dos CDI, em $40 \%$ a $70 \%$ das lesões intraductais $^{(21)}$ e $10 \%$ dos carcinomas medulares ${ }^{(8)}$.

Neste trabalho, observou-se que mais da metade dos casos de CDI (76\%) apresentou marcação positiva para
cerbB-2, corroborando com os resultados de estudo recente, em que se encontrou uma positividade de $85 \%$ no mesmo tipo de carcinoma ${ }^{(17)}$. No entanto, diversos estudos detectaram a superexpressão de cerbB-2 em torno de 10\% a $30 \%$ dos casos analisados ${ }^{(23)}$ de tumores de mama do tipo CDI. De uma maneira geral, a superexpressão de cerbB-2 pode ser encontrada em $10 \%$ a $40 \%$ dos tumores de mama não-metastáticos ${ }^{(27)}$.

As discrepâncias entre os estudos têm sido explicadas e atribuídas às diferenças na metodologia e à variabilidade na sensibilidade da imuno-histoquímica, dependendo de diferentes clones do anti-Her-2/neu e suas perdas por causa de alterações antigênicas causadas no procedimento da fixação(20).

A amplificação do gene erbB-2 e a superexpressão da proteína cerbB-2 têm sido estudadas em uma variedade de tecidos com tumores malignos, entre os quais estão: pulmão, em que foi demonstrada a amplificação gênica em 1,6\% dos casos analisados ${ }^{(26)}$; ovário, que é objeto de um maior número de pesquisas, mas com resultados contraditórios, enquanto alguns pesquisadores encontraram uma alta positividade ${ }^{(14)}$, outros trabalhos mais recentes demonstram a ausência da expressão da proteína em ovário(20); próstata, em que foi demonstrada a superexpressão de cerbB- $2^{(13)}$, como também em intestino(25).

Uma das razões para o presente estudo investigar a expressão de cerbB-2 em tecidos mamários com FA se deve ao fato de que esse distúrbio tem sido correlacionado a vários processos neoplásicos na mama. Embora a explicação para esse fenômeno esteja longe de ser encontrada, determinar os aspectos comuns e distintos para essa doença e suas respectivas complicações tem atraído cada vez mais 0 interesse dos pesquisadores ${ }^{(4)}$.

O FA é um tumor benigno frequente, formado por componentes epiteilais e estromais, que ocorre geralmente em mulheres jovens e raramente está associado ao desenvolvimento de malignidade. Entretanto, em revisão de 22 anos da literatura, foram encontrados 16 casos de carcinoma com $\mathrm{FA}$, dos quais 18,8\% eram carcinomas ductais in situ (CDIS), 37,5\% eram CDI, 37,5\% carcinomas lobulares in situ (CDLIS) e 6,3\% carcinomas lobulares invasivos (CLI)(1). O pequeno número de casos de FA com carcinoma é refletido por poucos trabalhos e estudos de casos, além do fato de o comportamento desses tumores ainda não estar bem definido(18).

No presente estudo, não foi observada a expressão do cerbB-2 nos tecidos normais nem com FA; no entanto, um estudo realizado pela DAKO, para esclarecimento dos 
usuários dos kits comercializados por essa empresa, demonstra a expressão dessa proteína em tecido normal de alguns órgãos, como mama, rim, pulmão, pâncreas, próstata, pele, estômago e tonsila( ${ }^{(6)}$. Quanto ao FA, durante a revisão da literatura deste trabalho, foram encontrados poucos relatos sobre a pesquisa de marcadores de proliferação ou transformação nesse tipo de tumor, e em nenhum dos casos foi indicado um aumento da expressão dos marcadores.

Outro fator prognóstico que os marcadores teciduais têm ajudado a estabelecer é a idade média dos pacientes portadores de lesões tumorais malignas e benignas. Neste estudo, a idade média das pacientes com diagnóstico de CDI foi de 52 anos, enquanto as que possuíam FA apresentaram uma idade média de 36 anos, confirmando os achados da literatura de que o FA geralmente acomete mulheres mais joven ${ }^{(1)}$, enquanto os carcinomas de mama surgem, na maioria dos casos, em idade mais avançada.

O método imunohistoquímico é atualmente o método mais empregado para a detecção de cerbB-2, sendo mais conveniente que outras análises, não somente porque a técnica é mais fácil, mas também porque existem evidências de que a despeito da alta correlação entre a amplificação do gene e a expressão aumentada de cerbB-2, esta última pode estar presente sem a amplificação do gene ${ }^{(8)}$.

As principais vantagens dos métodos convencionais de imuno-histoquímica podem ser assim resumidas:

- possibilidade de ser realizado na maioria dos laboratórios;

- rapidez;

- necessidade apenas de microscópio de luz comum para visualização e interpretação dos resultados;

- associação com evolução clínica.

As principais desvantagens são:

- grande variedade de anticorpos disponíveis no mercado e com graus de antigenicidade distintos;

- utilização de diferentes tipos de sistemas de detecção;

- falta de padronização do método escolhido para recuperação antigênica;

- ausência de limites padronizados para definição de negatividade e positividade e distinção entre os diversos graus de positividade;

- falta de um padrão de escore definido.

Nas análises realizadas neste estudo, observou-se que a reação imonohistoquímica positiva para cerbB-2 apresentava um padrão de marcação de membrana celular, sendo desconsiderada qualquer marcação inespecífica em outras estruturas celulares, como por exemplo o citoplasma celular ${ }^{(11)}$. O padrão de marcação obtido neste trabalho está de acordo com os dados relatados pela literatura recente.

Embora não exista um consenso com relação à maneira de quantificar os diferentes padrões de marcação, na rotina costuma-se utilizar os scores qualitativos que estabelecem a seguinte classificação: 0 ou - quando há marcação em menos de 10\%, (1+) para marcação fraca em mais de $10 \%$ das células, (2+) se a marcação for fraca a moderada em mais de $10 \%$ das células tumorais, $(3+)$ quando há uma marcação intensa em mais de $10 \%$ das células tumorais ${ }^{(20)}$. Entretanto, muitas vezes essa classificação não demonstra muita acurácia científica, embora seja utilizada para o direcionamento da terapêutica a ser administrada aos pacientes ${ }^{(8)}$.

Quanto ao sistema computadorizado de imagens utilizado, neste trabalho pode-se observar que as diferentes etapas, desde a captura, o processamento e a análise morfométrica das imagens, foram executadas em um tempo médio de 10 minutos para cada lâmina analisada, o que demonstra que, após a calibração inicial do equipamento, o método proposto não se configura uma técnica muito demorada.

Tanto na prática clínica como em trabalhos experimentais, é fundamental a utilização de métodos para quantificar parâmetros relevantes observados na formação de tecido tumoral(3).

Vários trabalhos têm empreendido a utilização de métodos morfométricos computadorizados para o estudo de distúrbios morfológicos da mama ${ }^{(5)}$. Entretanto, o número de trabalhos com análise de imagem em estudos imunohistoquímicos em mama é pequeno, mas aqueles que o fazem relatam ganhos significativos, principalmente como um instrumento de relevante valor prognóstico ${ }^{(28)}$.

Com base nos resultados recentes obtidos em nosso laboratório, a partir da análise morfométrica utilizando o sistema de análises Optimas ${ }^{\mathrm{TM}}$ 6.1, pode-se constatar a eficiência desse sistema para avaliar tecidos marcados com a técnica de imuno-histoquímica ${ }^{(19,3)}$.

Todavia, existem algumas limitações, como padronização (calibração), alto preço do equipamento e longo período de treinamento, que podem ser as causas da lenta implantação dessa metodologia nos laboratórios de patologia, tanto para uso na rotina histológica como para utilização em imuno-histoquímica de tecidos com lesões tumorais(3). 
O desenvolvimento e a execução de metodologias automatizadas podem trazer um grande benefício para a rotina clínica, sendo útil para o controle de qualidade e a quantificação exata da marcação imuno-histoquímica. Alguns autores enfatizam a possibilidade do armazenamento dos dados e das análises realizadas, o que torna possível uma reavaliação a qualquer momento. Dessa maneira, os assistentes técnicos podem executar uma pré-análise que pode ser validada posteriormente pelo perito e ainda ser usada como ferramenta para formação de novos profissionais ${ }^{(12)}$.

Com base nesses aspectos, diferentes trabalhos constataram maiores precisão, sensibilidade e reprodutibilidade dos sistemas de quantificação semiautomáticos frente ao método manual em diferentes tipos de tecidos ${ }^{(12)}$. No entanto, esses sistemas também possuem suas áreas de conflito por não haver um sistema de referência bem definido (em área) para realizar a quantificação, por falta de consenso a respeito das unidades contábeis (células ou áreas marcadas) ou pela própria variedade de localização celular do marcador a ser identificado (nuclear, citoplasmático, membranar) $)^{(10)}$.

\section{Conclusão}

A partir dos resultados obtidos, pode-se concluir que não há diferenças significativas entre os diferentes scores qualitativos $(1+, 2+$ e 3+) e a análise morfométrica digital (áreas número médio de tecido marcado), o que no mínimo demonstra necessidade de estudos mais acurados a fim de resolver essa disparidade de interpretação.

Constata-se, também, que a superexpressão do cerbB-2 em casos de CDI é um fenômeno condizente com o estágio de proliferação das células neoplásicas malignas e que, referente a esse marcador específico, não parece haver qualquer correlação com o padrão de expressão nos casos de FA analisados que, pelo contrário, apresentaram resultados semelhantes ao tecido mamário normal.

\section{Referências}

1. ABE, $\mathrm{H}$. et al. Invasive ductal carcinoma within a fibroadenoma of the breast. Int J Clin Oncol, v. 9, p. 334-8, 2004

2. ARAÚJO-FILHO, J.L.S. et al. Galectina-3 em tumores de próstata: imuno-histoquímica e análise digital de imagens. J Bras Patol Med Lab, v. 42, n. 6, p. 46975, 2006

3. BARBOSA-JÚNIOR, A.A. Morphological computer-assisted quantitative estimation of stained fibrous tissue in liver sections: applications in diagnosis and experimental research. J Bras Patol, v. 37, n. 3, p. 197-200, 2001.

4. CALADO, S.S.; LIMA, M.C.C.A. Estudo morfolígico dod fibroadenomas da mama: uma análise comparativa entre grupos etários. J Brás Med Lab, v. 40, n. 6, p. 411-19, 2004.

5. CARTER, J.K. et al. A computer model for the study of breast cancer. Computer Biol Med, v. 33, p. 345-60, 2003.

6. DAKO. HercepTest ${ }^{\mathrm{TM}}$ Interpretation Manual. 2002. Disponível em: http://www.Dakocytomation.com. Acesso em: 25 maio 2007

7. DUBSKÁ, L.; ANDERA, L.; SHEARD, M.A. ER2 signaling downregulation by trastuzumab and suppression of the PI3K/Akt pathway: An unexpected effect on TRAIL-induced apoptosis. FEBS Letters, v. 579, p. 4149-58, 2005.

8. EINSENBERG, A.L.A.; KOIFMAN, S. Câncer de mama: marcadores tumorais (revisão da literatura). Rev Bras Cancerol, v. 47, n. 4, p. 377- 88, 2001.
9. GANCEBERG, D. et al. Sensitivity of Her-2/neu antibodies in archival tissue samples of invasive breast carcinomas. Correlation with oncogene amplification in 160 cases. Anat Pathol, v. 113, p. 675-82, 2000.

10. GIL, J.; WU, H.S. Applications of image analysis to anatomic pathology: realities and promises. Cancer Invest, v. 21, n. 6, p. 950-9, 2003.

11. GOUVÊA, P.A.; FERNANDES, J.R.M.; OLSON, S.J.; BRANDÃO, E.C.; LEITE, M.T.; GOBBI, H. Her-2/neu immunoreactivity in invasive mammary carcinomas: a comparative study using monoclonal and polyclonal antibodies including the HercepTest ${ }^{\mathrm{TM}}$. J Bras Patol Med Lab, v. 40, n. 1, p. 27-32, 2004.

12. HILBE, W. et al. Comparison of automated cellular imaging system and manual microscopy for immunohistochemically stained cryostat sections of lung cancer specimens applying p53, ki-67 and p120. Oncol Reports, v. 10, n. 1 , p. $15-20,2003$

13. KALLAKURY, B.V. etal. Correlation of $p 34^{\text {cdc2 }}$ cyclin-dependent kinase overexpression CD44s dowregulation, and HER$2 /$ neu oncogen amplification with recurrence in prostate adenocarcinomas. J Clin Oncol, v. 16, p. 1302-9, 1998.

14. KING, L.A. et al. Mitotic count, nuclear atypia, and immunohistochemical determination of Ki-67, c-myc, p21-ras, c-erbB2, and p53 expression in granulosa cell tumors of the ovary: mitotic count and Ki-67 are indicators of poor prognosis. Gynecol Oncol v. 61, p. 227-32, 1996. 
15. KOBAYASHI, M. et al: Protein overexpression and gene amplification of cerbB-2 in breast carcinomas: A comparative study of immunohistochemistry and fluorescence in sito hybridization of formalin-fixed, paraffin-embedded tissues. Human Pathol, v. 33, p. 21-8, 2002.

16. LEE, C.M. et al. Expression of Her-2/neu (cerbB-2) epidermal growth factor receptor in cervical cancer: prognostic correlation with clinical characteristics and comparison of manual and automated imaging analysis. Gynecol Oncol, v. 93, p. 209-14, 2004.

17. MADAN, R. et al. Focal adhesion proteins as markers of malignant transformation and prognostic indicators ina breast carcinoma. Human Pathol, v. 37, p. 915, 2006.

18. MARUBASHI, S. et al. A case of breast cancer arising in fibroadenoma (in Japanese). Jpn J Clin Surg, v. 60, p. 2057-61, 1999.

19. MELO-JUNIOR, M.R. et al. Langerhans cells in cutaneous tumours: immunohistochemistry study using a computer image analysis system. J Mol Histol, v. 37, p. 321-5, 2006

20. MENCZER, J. et al. Is Her-2/neu expressed in nonepithelial ovarian malignancies? Am J Obstet Gynecol, v. 196, p. 79.e1-79.e4, 2007.

21. MONTIRONI, R. et al. HER2 expression and gene amplification in pT2a Gleason score 6 prostate cancer incidentally detected in cystoprostatectomies: comparison with clinically detected androgendependent and androgen-independent cancer. Human Pathol, v. 37, p. 1137-44, 2006.

22. OLIVEIRA, A.B. et al. Imunoexpressão do cerbB-2 nas lesões epiteliais proliferativas intraductais da mama de mulheres. Rev Assoc Med Bras; v. 50, n. 3, p. 324-9, 2004.

23. REED, W. et al. The prognostic value of $p 53$ and cerbB-2 immunostaining is over-rated for patients with lymph node negative breast carcinoma. Cancer, v. 88, p. 804-13, 2000.

24. SALES, A.O.; RODRIGUES, S.J.P.; BACCHI, C.E. Estudo comparativo entre os métodos $\mathrm{LSAB}^{\circledR}+$ e Herceptest $^{\circledR}$ para a detecção de Her-2/neu em carcinoma de mama. J Bras Patol Med Lab, v. 40, n. 4, p. 265-71, 2004.

25. SCHUELL, B. et al. Her-2/neu protein expression in colorectal cancer. BMC Cancer, v. 6, p. 123, 2006.

26. SHIGEMATSU, $\mathrm{H}$. et al. Somatic mutations of the HER2 Kinase Domain in lung adenocarcinoma. Cancer Res, v. 65, n. 5, p. 1642-6, 2005.

27. SILVA, D.M.; SADDI, V.A.; MOMOTUK, E.G. Marcadores moleculares associados ao câncer de mama não metastático. Rev Bras Cancerol, v. 48, n. 1, p. 3948, 2002.

28. TAWFIK, O.W. et al. Comparison of immunohistochemistry by automated cellular imaging system (ACIS) versus fluorescence in-situ hybridization in the evaluation of HER-2/neu expression in primary breast carcinoma. Histopathol, v. 48, n. 3, p. 258-67, 2006.

29. VAN BEMMEL, J.H.; MUSEN, M.A. Biostatistical Methods. In Handbook of medical informatics. Springer-Velag (Ed.) Germany, p. 387-96, 1997.

30. YAMAUCHI, H. et al. Prediction of response to antiestrogen therapy in advanced breast cancer patients by pre-treatment circulating levels of extra cellular domain of the HER-2/c-neu protein. J Clin Oncol, v. 15, p. 2518-25, 1997.

\section{Endereço para correspondência}

Mario Ribeiro de Melo-junior Laboratório de Imunopatologia Keizo Asami (LIKA) - UFPE Av. Prof. Morais Rêgo, s/n - Campus Universitário CEP 50670-910 - Recife-PE

e-mail: mariormi@gmail.com 